\title{
Learning Innovation of Area-Based Approach to Sustainable Development Goals of Highland Community Resources Management of Social Studies Teachers in the Northern Thailand
}

\author{
Charin Mangkhang ${ }^{1}$ \\ ${ }^{1}$ Faculty of Education, Chiangmai University, Chiang Mai, Thailand \\ Correspondence: Charin Mangkhang, Faculty of Education, Chiang Mai University, 239 Huay Kaew Rd, Suthep, \\ Mueang District, Chiang Mai, 50200, Thailand. E-mail: charin.mangkhang@cmu.ac.th
}

Received: July 3, $2021 \quad$ Accepted: July 20, $2021 \quad$ Online Published: July 28, 2021

doi:10.5539/hes.v11n3p95 URL: https://doi.org/10.5539/hes.v11n3p95

\begin{abstract}
The research aimed to study the context of area-based approach learning management and guidelines of area-based approach learning management for sustainable highland community resource management of social studies teachers in the learning center for Thai hill tribe communities in northern Thailand. The method of qualitative research was used. Purposive sampling was conducted to obtain key informants which were social studies teachers of the highland learning center, accounting for 285 people. This area is a development area of the royal project. Learning center for Thai hill tribe communities in northern Thailand have accessed to organize social studies teaching at the basic education level. The tools used in the research consisted of in-depth interviews and focus group discussion recording. Then, content analysis was conducted.

From the research result, it was found that the context of area-based approach learning management for sustainable highland community resources management of social studies teachers consisted of: executing the process of area-based management by surveying and collecting village data to be used as knowledge in learning management for pre-school students and students of basic education and the illiterate; developing occupations for the interested group in communities; developing life skills by using the method of coordination with community leaders; building local networks; participating in meeting with the community ;and exchanging information in order to inform people in the community of external exchanges. Regarding the use of area-based knowledge of social studies teachers, they have implemented the knowledge until this has brought about guidelines for promoting community resources management. For example, the community has participatory development plans. The community has networks of natural resources and environmental conservation and citizens have local conscience. Results of sustainable highland development are the fact that the community has strong power in conserving traditions, inheriting tribe cultures, establishing local herbal plants groups to take care of community health. Moreover, there are groups developing local products, building community declarations and regulations for living together in the community peacefully. The guidelines of area-based approach learning management for sustainable highland community resource management of social studies teachers consisted of 5 components which were FPCIL, namely (1) F: Facilitator, (2) P: Participatory assessment and planning, (3) C: Community capital value added, (4) I: Innovation of knowledge and (5) L: Lesson-learned.
\end{abstract}

Keywords: area-based approach, social studies teachers, highland community, sustainable development goals

\section{Introduction}

For the context of northern Thailand, the north of Thailand is characterized by highlands. These areas are habitats of populations settling down for living and making the land to the occupation. The highland with slopes lies 500 meters above the sea level. The highland covers areas of about 67.22 million rai, accounting for 53\% of the total area in 20 provinces. Areas on the highland where communities are located at are mostly rich abundant watershed forests. Due to the fact that there is communication difficulty accounting for $88 \%$ of the village, government agencies cannot access to operate development work on the highland thoroughly. Moreover, the highland has environmental problems and ongoing problems of agricultural land extension. In terms of social aspects, the population of the highland consists of ethnics for 15 tribes with the population of 964,916 people spreading out in villages for a total of 3,829 house groups. Most of these people scatter in 12 provinces, 
accounting for 851,282 people or $88.22 \%$ of total Thailand's mountain people in the country. Chiang Mai province has the most number of Thailand's mountain people, accounting for 244,291 people $(25.31 \%)$. This is followed by Tak province and Chiang Rai province, accounting for 130,065 people and 130,054 people respectively (13.47\%). All this time, the government has placed importance on highland development continuously whereby during the period of 1955 to 1969 , the government placed importance on solving security problems by looking into the problems of these highland people as minority groups. Main government agencies of the operation are Border Patrol Police Bureau and Department of Public Welfare. At the beginning in the period of 1969 to 1991, the government focused on solving the problem of growing plants with addictive substances along with solving the security problem mainly. Later on, integrated development was emphasized. However, importance needs to be placed on solving current highland problems continuously regarding accessing quality education, poverty problems, drugs and low incomes (Highland Research and Development Institute (Public Organization), 2012).

Results from the survey for making strategic plans of Highland Research and Development Institute (Public Organization) for the third period (2017-2021) revealed following facts: 1) Farmers in highland communities of Royal Project development areas had farmer households with poverty accounting for $23 \%$. Farmer households with poverty in terms of food accounted for $17 \%$. Poverty has brought about social problems. There have been corruptions. People do not have opportunities to access quality educational services. There has been scramble for resources (Highland Research and Development Institute (Public Organization), 2017). The main cause of poverty is due to the fact that farmers have low yields, high costs of production while production prices are low to some extent. Moreover, farmers do not have many marketing channels and they do not have an opportunity to create incomes outside agricultural sectors as they should; 2) Farmers have the production system which uses inappropriate agricultural chemicals. As a result, there have been contaminations of agricultural chemicals, residues both in products and the environment for soil and water. Most causes are due to the fact that farmers on highlands lack knowledge and skills for suitable cultivation. This affects the water resource system and inhabitants on lowlands as well; 3) Areas for making a living of agricultural land accounting for $96.48 \%$ of highlands in northern provinces have been degraded. Population in households has been increasing. Immigration of population out of the country and lowlands of Thailand have increased encroachment on forest land more and more; 4) There have been conflicts in using natural resources especially between the community in the upstream area and the community in the downstream area, including conflicts between the sate and the community. This happens because each side has different standpoints and viewpoints of making use of natural resources for soil, water and forests. $77.74 \%$ of farmer households on highlands in 12 provinces rely on forestation for use in households; 5) Regarding problems in the future, highland communities scatter and they have certain cultures. They hold on to community rules and religious beliefs, and use them as a frame for living and building peace in the society. These characteristics make the community have little immunity towards changes. Currently, the society of highland communities is open to the outside world more, resulting in being vulnerable to problems, namely youth problems, lack of conscience to the society, drug epidemic, AIDS, including security problems along the border. At the same time, the youth on highlands tend to migrate to cities more to make a living, resulting in shortage of workforce in the community (Aekkasing \& Pronburom, 2002; Highland Research and Development Institute, 2012).

Therefore, education for sustainable development goals (SDGs) is used as an important instrument in the society all over the world to develop citizens for building strength to the community, at its heart are the 17 sustainable development goals, which are an urgent call for action by all countries - developed and developing - in a global partnership. They recognize that ending poverty and other deprivations must go hand-in-hand with strategies that improve health and education, reduce inequality, and spur economic growth - all while tackling climate change and working to preserve our oceans and forests. (The United Nations, 2015). For developed countries, people in the society all have been developed educationally with qualities first. After that, other aspects are focused for development. These important reasons make every sector start to become aware of and place importance on education for sustainable development more. It became clear when National Education Act 1999 and additional amendment (Second Edition) 2002 prescribed the essence regarding the participation of parents, stakeholders, organizations and agencies. They participate in organizing and developing education. This can be done by allowing the society to participate in education management. Educational institutes can cooperate with stakeholders, communities of every sector in order to develop student according to their potentials. The mentioned essence and principles are specified in National Education Act.

Regarding the guideline of education management for sustainable development, the principle of education management for sustainable development consists of 1) abilities in competition based on resources and abilities 
of institutes 2) abilities in meeting the demand of students and groups of stakeholders and 3) abilities in adapting to the local context and universality (Panyanuwat, 2014). Therefore, people are the important key which leads to sustainability. This is due to the fact that if economic growth is to be stabilized, distributing wealth thoroughly at every level, its foundation must come from other factors especially from education management which must place importance on important variables related to curriculum and the teaching process. The objective is to make this support workforce production with abilities to have occupations and create one's own innovations to be recognized, including abilities to compete internationally. The development concept of Thailand for the past two decades has placed importance on economic growth mainly. This is not in balance with development in other aspects. Regarding the concept about national development since the first national economic and social development plan, although the development has made the economy grow, the growth has weak development foundation, resulting in lack of fair income distribution. Moreover, environmental crisis is not taken into consideration as it should be. Therefore, growth which is no in balance and not sustainable is the origin of the economic crisis which makes Thai ways of life start to lack balance with the environment. This turns to be accumulated problems deteriorating life qualities of the Thai people up to now. This will lead to development without direction if the development paradigm is not changed to be suitable and in balance holistically in terms of economical, social and environmental dimensions (Dhammapitaka, 2006; Siribunnapitak, 2010).

The roles and duties of social studies teachers in the Mae Fah Luang Learning Center for Thai hill tribe communities in Northern Thailand or Highland Community Education Center have been in operation since 1980 where by major roles of highland educational management are: 1) Educational management for life and society. This refers to educational management in which students can learn from methods of daily living as normal in every matter from ways of living, sleeping, illness, working, resting, entertaining.; 2) Educational management for the entire people. This refers to educational management which meets the demand of everyone in the community. Students can seek for choices and opportunities to learn as much as time and opportunity which each student will have for learning.; and 3) Lifetime educational management refers to learning based on methods both formal and non-formal education and informal education. This learning originates from motivation in learning throughout one's life span in which one must learn everything about living. Therefore, one must seek for knowledge all the time in order to be able to adapt oneself and live appropriately. The goal focuses on making the society develop life qualities at the person, family and the community level to be strong, bringing about basic skill development to see ways for further learning. Moreover, people will be able to manage the environment and resources appropriately. Communities will be in the state of learning society. People will become good citizens of the nation and be able to maintain cultures and ethnic wisdoms.

The mission of the Center is to send volunteer teachers or so-called by villagers as "Kru Doi (Mountain teacher)" for 1-2 people to embed themselves with people in highland communities. Buildings called "Arsom" are constructed with local materials in order to provide education services and develop communities to adults at night, and teach children from kindergarten to grade 6 of primary education (Prathom 6) at daytime. The objective focuses on making them able to help themselves and become good citizens of the nation. In fact, this project of community learning centers was given an award from UNESCO organization in 1994 as new concept in community-based educational management. This has expanded to wilderness areas for 773 locations. Somdet Phra Srinagarindra Boromarajajonani received every learning centers under patronage. Later on in 1996, Department of Non-Formal Education was aware of the royal grace. Therefore, it respectfully informed King Rama IX, requesting a royal name of Highland Community Education Center. Then, he gave a new name for Mae Fah Luang Learning Center for Thai hill tribe communities. "Mae Fah Luang" or "Somdej Ya" is a given name of Somdet Phra Srinagarindra Boromarajajonani. The abbreviated name for "Sor.Sor.Chor." is still used (Non-Formal Education Administration Office, 2003; Chiang Mai Non-Formal Education Center, 2005).

Therefore, educational management of social studies teachers is knowledge capturing by using it as conceptual framework "Learners as Makers" of Dewey (1963 Nonaka \& Takeuchi(1995). This happens during teachers' working together with the community, which reflects extraction of thinking methods. Thought, personnel's experiences embedded in highland operation, changing experiences into expertise to make communication possible are,therefore, distilling lessons learned. This is the process which emphasizes reinforcement of group learning, atmosphere supporting exchanges, learning to distill wisdom knowledge in practice embedded from individuals, communities, foundations, organizations or target agencies to be lessons. These lessons can be summarized, synthesized and applied. Learning organization is the concept in developing organizations by focusing on leadership learning development in organizations and team learning of people in the organization. The objective is to bring about transferring and exchanging knowledge, experiences and skills together, and developing the organization continuously to keep up with the state of changes and competition. Having learning 
organization will make organizations and personnel have the efficient working process and effective performance by connecting forms of working as team working, building the learning process and building understandings to cope with changes. The team will have an opportunity to work. Decision-making empowerment is given to promote initiative atmosphere and innovation building. This will bring about strong organizations, ready to confront competition (Peter M. Senge,1990; Burlington, Mass, 2005; Dalkir, Kimiz, 2005; Elias M. Awad, Hassan M. Ghaziri., 2004). The community learning center has cooperated with Highland Research and Development Institute (Public Organization) in the knowledge management project and the learning process for sustainable highland development and transferring knowledge of the royal project to highland communities. This will be done by using learning networks and transferring technology from the royal project. Moreover, there is also the process of community learning exchanges to make the community have appropriate occupations and live together with the environment sustainably. This also includes building social immunity, reinforcing good well-being, keeping cultural values, reinforcing morality and having conscience of being a Thai person with qualities.

From learning the area-based approach, which is action learning used in the project supervising the operation of the knowledge management project and the learning process for sustainable highland development in the past, the researcher wanted to study the context of area-based approach learning management and the form of area-based approach for sustainable resource management of highland communities of social studies teachers in the Learning Center for Thai hill tribe communities to learn about the process in this matter. Highland Research and Development Institute (Public Organization) is the civil society organization supporting ongoing highland development. The objectives are for the benefit in reviewing the transfer of royal project knowledge for sustainable highland development, the transfer royal project technology and knowledge to highland communities with the goal of focusing on social studies teachers in the Mae Fah Luang Learning Center for Thai hill tribe communities scattering all over the area. Lessons learned are expected to be distilled to bring about knowledge to transfer to the community learning center. The operation has been successful in some areas. However, there are some areas which needs reinforcement to be strong. Different ways of learning and forms of area-based approach learning result in different potential of learning centers. Research conducted to seek for the form of knowledge management leading to success in operation according to the mission of the community learning center can bring about mental values which will be important foundation in developing civic education of schools with learning management of the community on highlands further.

\section{Method}

Qualitative research was used in this research, focusing on presenting hermeneutic phenomena data which emphasize interpretation of lessons obtained from interviews, focus group discussion in which teachers expressed their feelings originating from embedding in highland communities of Learning Center for Thai hill tribe communities. (Phosita, 2007; Chantawanich, 2007; Yin, 2014).

\subsection{Target Groups}

Key informants accounted for 285 people whereby the data obtained from them were categorized into 2 parts. Part 1 consisted of data obtained in-depth interview specifically conducted with social studies teachers in the project supervising the operation of the knowledge management project and the learning process for sustainable highland development. They had taught in Learning Center for Thai hill tribe communities for at least 1 academic year. They also volunteered to give data and were able to reveal that they were teachers of the learning center the area of Northern Thailand. Part 2 consisted of data from focus group discussion obtained from social studies teachers with excellent practices in the area of Chiang Mai for 5 districts, namely Jomthong, Fang, Chiangdao, Mae Tang and Mae Jam. They implemented the knowledge to manage learning until excellent practices occurred in the learning center. They were willing to participate in the focus group discussion in order to exchange learning regarding the approach of learning management for sustainable highland development, accounting for 30 people. The research team made an appointment for focus group discussion of learning-center teachers during yearly work presentation of schools in the area of the royal project organized in Chiang Mai by Royal Project Foundation.

\subsection{Study Areas}

The community learning center in the royal project development area in Northern Thailand where social studies teachers operated according to the action plan of Royal Project Development Center in educational management for life quality development in highland communities was used for study areas. They applied intentionally and voluntarily to participate in the project supervising the operation of the knowledge management project and the learning process for sustainable highland community resources management by allowing the researcher to enter 
the area to study, observe learning management in the area of the learning center in the area of Chiang Mai province. They were willing to accept supervision and build the supporting process with trust. There were 5 locations for 26 villages, namely: Ban Mae Klang Luang Community Learning Center, Chom Thong district; Ban Thub Takien Community Learning Center, Fang district; Ban Huay Pong Community Learning Center, Chiang Dao district; Ban Huay Prachao Community Learning Center, Mae Taeng district; and Mae Jum Sam Community Learning Center, Mae Chaem district, Chiang mai province.

\subsection{Research Instruments}

The researcher used an in-depth interview form. to gain insights into the sample In the interview, the process of disguise is used to create interaction. and familiarity with data collection and recording data of focus group discussion which the research team built according to the research objective were also used. Instrument qualities were validated by 5 experts consisting of: Director of Highland Research and Development Institute, accounting for 1 person; Director of North Non-Formal Education and Informal Education Institute accounting for 1 person; Director of Provincial Non-Formal Education and Informal Education Promotion Office accounting for 1 person; Instructors from Institution of Education specializing in teaching about community knowledge management accounting for 2 people. Examples of some of the framed questions in the in-depth interview: "Regarding the context of learning management for sustainable highland development of social studies teachers in the learning center in the area, what is it like?"; "What methods do social teachers use to develop highlands sustainably?"; "In what manners do social studies teachers use the knowledge of the royal project for sustainable highland development?" Issues used in the focus group discussion: "How do social studies teachers approach knowledge management for sustainable highland development?"; "What important components do social studies teachers use in knowledge management for sustainable highland development?".

\subsection{Methods of Data Collection}

\subsubsection{Observation}

Entering the field to study the operation area of the teachers and coordinate, asking for cooperation in transferring data and knowledge through in-depth interviews in order to study the context of learning management in highland communities in northern Thailand, namely area-based learning management, area-based knowledge use, and social studies teachers' knowledge transfer in the learning center

\subsubsection{Interview}

Studying, collecting, and synthesizing knowledge from documents related to highland development, preparing knowledge database, action plans of Area Royal Project Development Center of the project supervising the operation of the knowledge management project and the learning process for sustainable highland development.

\subsubsection{Focus Group Discussion}

Conducting focus group discussion after teachers' operation regarding the knowledge management approach and important components in managing knowledge for sustainable highland development.

\subsection{Trustworthiness of Data}

Checking qualitative data, verified for facts by social studies teachers embedding in the community learning center. Triangulation was used, namely 1) Checking from different data sources such as checking from documents, people, field recording and 2) Using different collecting methods such as studying from documents, interviewing, focus group discussion and checking data by categorizing data into 2 parts which were evaluative data and descriptive data and then analyzing the data to be consistent with real conditions

\subsection{Data Analysis}

Data analysis started with making an appointment with district supervising teachers and social studies teachers in the community learning center to enter the area. This was done together with in-depth interviews in the area where the researcher emphasized intimacy and communication with respect, befriending. Video recording for pictures and sound was asked for permission. Questions did not lead but it was the matter of waiting for answers from informants' willingness. The answers from interviewing regarding the context of learning management for sustainable highland development according to the real situation in which the teachers were working were analyzed in details for finding issues (thematic analysis) to be used to determine the frame of focus group discussion. Then, the obtained data were grouped for similar or related data. Common issues were to be found to find data for supporting important components in sustainable highland development so that the research would have trustworthiness. The obtained data were presented to the informants for verification and adding missing data so that research results would be more complete. Data analysis was conducted according to the conceptual 
framework and research objectives through the method of content analysis. The data obtained from studying documents and occurring phenomena according to real situations from field observance, interviewing and focus group discussion were arranged for the data system into categories. The data were given meaning by interpreting the obtained data to be key words or statements conveying meaning of the collected data. Then, conclusion was made and the data were made into categories whereby data analysis was an interpretation manner to find meanings consistent with research questions (Phosita, 2007; Chantawanich, 2007 \&Yin, 2014).

\section{Results}

The context of area-based approach learning management for sustainable highland community resources management for sustainable of social studies teachers in the Learning Center for Thai hill tribe communities in northern Thailand obtained from in-depth interview consists of 3 important aspects:

Area-based approach learning management of social studies teachers who have duties of educational management at the learning center. They have ideology and have faith in being a teacher at the most. They have knowledge and understandings in organizing activities well. They have skills in organizing teaching and producing teaching medias. They develop themselves continuously. They yearn for knowledge regularly. Teachers has ways of operation for area-based learning management as follows: 1) Surveying village data to be used as data for organizing learning activities; 2) Organizing learning for preschool students; 3) Organizing learning for the illiterate students and occupation development for interested people in the community; 4) Organizing learning in terms of life skills development; 5) Coordinating with community leaders and local networks in organizing activities; 6) Attending the meeting with the community; and 7) Informing people in the community of information and news so that they will know about changes from the outside world. Regarding problems, it was found that most teachers at the learning center lack learning planning connected and consistent with reality in the holistic community context. In fact, each community learning center can use community basic data and social capital to be the main guideline in learning management, namely ethnics, population structures, languages and beliefs, traditions and cultures of the community, government leaders for both formal leaders and natural leaders, leaders in the community, economic systems, community problems. Moreover, there is lack of promoting student to record learning after implementation regarding occupations and ways of life. Although students understand activities of teaching from knowledge transferred to by the royal project through various medias, learning obstacles of students are the fact that they lack skills in terms of reading, speaking and writing Thai. In fact, they are basic skills important in learning of students in the non-formal education system. Teachers should insert skills of using the Thai language in the operation regularly and naturally. Doing this will help promote and support student so that they can extend knowledge and integrate knowledge continuously and sustainably.

Regarding area-based knowledge, social studies teachers have good knowledge and understandings in the area of the community learning center. There is knowledge use of the royal project in 2 characteristics which are knowledge of community basic data in the area of the royal project or the development center where the royal project is located at and knowledge which the royal project has developed and promoted in the community and teachers cooperate with the community in conserving natural resources and the environment, conserving customs, arts, cultures of the tribe, developing dwellings, caring for health and sanitation and providing education services to people in the community thoroughly. The concept of populace wisdom has been used as the approach frame in using area-based knowledge in which there are leaders and committee of the learning center as coordinators to bring about cooperation, being united in spirit, promotion and support as stakeholders and service receivers. The teachers implement area-based knowledge until good practices occur. For example, the community has participatory development plans. The community has networks of natural resources and environmental conservation. Citizens have local conscience. Results of sustainable highland development are the fact that the community has strong power in conserving customs, passing on cultures of the tribe, establishing groups of local herbs to care for health and sanitation of the community. There are also groups developing local products. The community has made declaration and regulations of the community for living together in the community peacefully. Regarding problems found, the teachers of several community learning centers cannot adjust acquired knowledge from the royal project to truly transfer to villagers. It is mostly a matter of using the content provided by Highland Research and Development without synthesizing the community context. This causes problems of communication leading to correct and matching knowledge and understandings. Therefore, the operation of the learning center is separated operation, resulting in the fact that operation of the project is not quite successful as it should be. Regarding knowledge of the royal project to be transferred through the community learning center to villagers, some knowledge is beyond experiences of true perception in real ways of life of villagers. Some knowledge existed previously. The royal project only gives a new definition to bring 
about matching knowledge and understanding such as economy for highland communities etc.

In regard to transfer of knowledge, every social studies teacher in the community learning center focuses on transferring knowledge an exchanging learning about occupation for creating incomes, life skills development and livelihood, including environmental conservation mutually integrated with agencies, organizations and communities in the area under the concept of sufficiency economy in physical forms and virtual areas in order to bring about to-know, to-learn and transform mutually under the paradigm of action learning. For problems, transferring knowledge with videos had so much difficulty beyond ethnic students' comprehension. There were lots of contents. The media form emphasized academically more than being learning medias for villagers with different languages, ethnicities and areas. For medias to be used with electrical appliances, several learning centers had problems with these because they did not have video players. Amount of electricity was limited and was not enough for transferring knowledge due to the fact that most highland learning centers had to use electric power from sunlight. For the Thai language used in the media and the learning community, there were contents of some topics which had to be interpreted and translated for new meanings because students only had basic knowledge and understandings at a low level. On top of that, there was a big problem for students who did not have any knowledge and understandings of the Thai language at all. The media used lacked pictures, learning activities both for virtual pictures and photographs. As a result, students became bored and this made it difficult for students to reach the knowledge required to transfer.

Guidelines of knowledge management of social sciences teachers in the learning center for sustainable highland community resource management were obtained from focus group discussion and the data were analyzed to connect with the determined issues. There were 5 important components found in sustainable highland development as follows:

1) Facilitator: F -Developing teacher qualities has reflected that social studies teachers must adjust their roles to be a facilitator by going through various processes originating from teachers' knowledge acquisition of teachers from socialization. Then, this is to be adjusted with the community and proceed to change proactive operations to be modern at all times by using information technology to integrate in knowledge management for sustainable highland management. Teachers' working for area-based development requires skills and knowledge of operational work indeed in order to being able to work to meet the objective, to stimulate villagers' learning to the point and to solve facing problems in the operational work. This is building confidence with the community in participating activities which teachers in the learning center organize.

2) Participatory assessment and planning: $P$ is the process of knowledge management in which social studies teachers in the area propose that making community plans together with villagers must emphasize participation of the people in the area in order to determine directions of sustainable highland development. This can be done by surveying basic data of the community, learning about community resources and the needs for development, understanding problems and obstacles. After that, this is used to determine goals and planning development together to bring about participatory community plans with mutual integration between all people involved. When the operation starts according to the plan, the plan must be reviewed regularly in order to be able to adjust the plan according to situations and to be in line with the direction of development which the community wants.

3) Community capital management: $\mathbf{C}$ is externalization. Social studies teachers view that the area-based development process through the dialogue method to build dialectic community capital has promoted the community to see available community capital values to extend sustainable highland development. Managing community resources to have value added is the approach to pull potentials of the community to be used as important mechanism of highland development. Teachers must open opportunities for the community to have roles of being leaders of changes in every process. Community-based development will bring about in terms of being sustainably creative. The community will be able to operate by itself further in the future, bringing about participatory area-based development by the community.

4) Innovation of knowledge: $I$ is combination of knowledge in the community to present teachers' knowledge into use through building innovation of knowledge in each community. Social studies teachers who work in the area of the royal project have presented knowledge originating from the community with storage, categorization, distilling, exchanges, propagation, techniques, methods of practices, secrets, or warning in order to be applied completely in every aspect. In any case, teachers must build prototype leaders in the community where knowledge is integrated with wisdom of the development area of the royal project, which is in line with the needs of the community mainly.

5) Lesson-learned: $\mathbf{L}$ is internalization to be used in sustainable highland development of the teachers. Social studies teachers organize activities in bringing theories to practices in order to build knowledge source from 
lessons which teachers and the community have practiced until they become experts. This takes time to be timely cultivated until achievement is reached. Therefore, the way the teachers distill the lesson learned must proceed gradually in order to obtain empirical sets of knowledge embedded in the community. Mistakes are learnt in order to obtain new methods. In sustainable development, this needs readjustment for many times until the goal is reached. Therefore, teachers, the developer must be patient and follow situations all the time. Teachers must not abandon the community even during difficult times when there are problems and obstacles in operation.

\section{Discussion}

From the research results, it was found that Key competency in learning management in high-altitude areas is the development of learning management to help students utilize digital resources in their learning. and the change from the traditional curriculum perspective to the curriculum of trans virtual competency to achieve equality and equality in society. following the Sustainable Development Goals (SDGs), where knowledge gaps can be discussed. and the findings are as follows:

Regarding the context of area-based approach learning management for sustainable highland community resource management of most social studies teachers in the learning center, it was found that social studies teachers still lack learning planning connecting and corresponding to reality in the holistic community context, promoting students to record learning after doing activities related to occupations and ways of life. As a result, learning management is not related to ways of life. There has been separated learning. This may be due to lack of understanding in the context of humanity with society. Separated operation leads to individual learning (Natsupa, 2005; Vallidophom, 2013). Therefore, the study on humans' learning requires knowledge management by adjusting ways of thinking so that people can understand and see connection of factors at the most. Then, humans can develop and solve problems of the community effectively and sustainably. They become aware of holism or integration of things and can manage community knowledge in an integrative manner without cutting down or separating parts of phenomena to manage without being in line with reality in the community (Daecharat, 2004). This is consistent with the study of Mangkhang, Jarupongputtana, Yimsawat, Buttong. (2015). They found that educational management for strong locality must meet the demand of students $\mathrm{n}$ reinforce power to students so that they will see values and understand community cultures, local identities. Moreover, students should be able to design their own learning freely. Likewise, the work of Foebes (2003) which presents educational values holistically supports students to have freedom in learning with enough flexibility so that students will not feel compelled to learn with haste. Students learn to consider facts and things which are occurring with good judgment for themselves, the society and the system on the whole by showing connection of themselves with the system regularly. This brings about development of the learning process with synchronistic relationships and promoting students to have a major part in managing their own learning (meta-learning), to develop social abilities and to be able to specify refining values. Students can learn efficiently if they learn about things which are meaningful and important to them. The study of Miller (2000) views that holistic education is educational management based on developing people to find meaning and goals in life through seeing their own relationships with the environment, communities, natural world, souls and all the mass of the universe system. It is also the learning which emphasizes students mainly and truly. In the community learning center with area-based knowledge integrated from populace wisdom, it was found that the community had community declaration which determined rules and regulations in order to live together peacefully. Organic intellectual originates from accumulating learning for a long time by connecting with science holistically with no separation into individual subjects like current education. This is in line with the work of Metkarunjit (2004) which presents that participatory educational management based on organic intellectual is regarded as valuable social capital which can be used to benefit sustainable community development. Students will become intellectual in using knowledge, abilities, experiences as well as cleverness to connect past experiences to be performance. This performance is to be used to solve problems and in daily living (Romeratanapun, 2005).

For knowledge transfer, every social studies teacher focuses on knowledge transfer, socialization regarding occupation development for making incomes, life skill development and livelihood, including environmental conservation on highland integrated together with agencies, organizations and communities in the area under the concept of sufficiency economy in order to create the atmosphere of to-know, to-learn and transform together under the paradigm of action learning. Therefore, this will lead to sustainable highland development. Knowledge transfer must have an important goal which is knowledge sharing. This knowledge sharing will help knowledge transfer become meaningful to area-based development work. This is in line with the work of Panich (2005) which reiterates that knowledge sharing is dynamic and a method of practice of people in the community, which helps build intellectual capital in the community.

Guidelines of knowledge management of social studies students find components which promote highland 
communities for sustainable development as follows: 1) Facilitator- Changing roles of teachers for community development in modern age which are not the same as education in the past appear in the work of Panich (2012). He gives a concept that quality education must change learning forms of students completely. Roles of teachers and instructors must change as well. Teachers for students must change interesting points or the focal point of teaching to the focal point of learning and improve learning forms organized to students. Teachers for students must change their roles from "teacher" to "coach" or "learning facilitator". They must learn the skills for this function by getting together as a group in order to learn together systematically and continuously which is called "professional learning community: PLC". Teachers of 21 st century must hold on to the principle " teach less, learn more :TLLM". Therefore, learning in the 21 st century must step across subjects to skills for living in the 21 st century ( 21 st century skills) which teachers cannot teach but students have to learn by themselves. However, teachers must design learning and facilitate learning so that students can learn by performing the action. Then, learning will occur in their mind and brains. It is the project-based learning (PBL) (Dewey, 1963); 2) Participatory assessment and planning (PAP) is determining future and development activities of the community. It originates from clustering of community people to make plans used as guidelines in developing their own communities or districts to be as they wish. Problems which the community is facing can be solved. People in the community participate in thinking, determining guidelines and do development activities together. They hold on to the principle of self-reliance, reduce external dependencies, take into consideration potentials, resources, wisdom, ways of life, culture and the environment mainly. It can be said that community plans belong to the community, are operated by the community and benefit the community itself. They are different from plans which government organizations have prepared for budget allocation mainly. Community plans reflect problems, needs of community from bottom up. Knowing that what problems are, what opportunities are, what potentials are obtained from studying factual data. Then, people help one another think to find solutions. After they have done things, they can learn from practices or from the community with good practices. People in the community must help check to see if there are any bottleneck issues, plans of all the people in the village. They mutually think, take actions to bring about understandings until they can drive the work of solving problems. Moreover, they have time for discussion more. There is more learning of the community which is consistent with ways of life. Commitment of people in the community tends to be sustainable and leads to better results.

Therefore, community plans play an important role in changing communities, namely (1) People become aware of themselves rather than villagers do according to agencies only. They get a hold of themselves, start to think and manage data and analyze problems. They also check development guidelines in order to lead to self-management. (2) There are data, data acknowledge, knowing why this matter is done and what changes this matter leads to. There is connection clustering to be mutual network working or connection relationships between different processes and (3) The process of making plans is changing relationships among villagers themselves and between villagers and agencies. This is regarded as very important subject matter and in line with the work of Naruethum (2008) and Pra Pokklao Institute (2013) presenting that participation in making local development plans must be open mind, listen to information from one another. Everyone has ideas. Thinking together is more valuable than any things else. "Every idea is valuable", which will make our community develop sustainably. In other words, everyone will live well together to be future citizens. Therefore, opportunities should be open to everyone to make community plans together. Everyone has freedom in participation and is not forced. Everyone must be able ot participate in activities and help build opportunities for them to be able to participate. Everyone is equal in expressing their opinions. No one has more power than other people because "each individual is a partner of idea" for mutual development. everyone has public mind to participate for the benefit of the community. 3) Community capital value added - Social values or social structures which brings about economic values in the highland community are trust, network and institution. Regarding social relationships of any forms which are social capital, at last can they benefit the community economically? Regarding community capital originating from mutual interactions, participatory activities. the more there is this community capital may be beneficial in terms of bringing about learning, perception and transferring information among one another, resulting in some values which can be strung up and accepted together. The occurring values promote economic values in the community sustainably whereby teachers in the community have activities with cooperation such as forest fire prevention, integrated agricultural plots activities, ordination of trees, performing ceremony of extending the fate of rivers. Community customs make villagers learn and understand or "know" one another well. Community capital is divided into 2 types which are cognitive community capital and structural community capital. Cognitive community capital is invisible and is difficult to assess because it lies in people's mind. This type of social capital involves feelings, mind, belief, attitude such as trust, share values and reciprocity. 4) Innovation of knowledge- Highland communities have knowledge originating from conduct of life and working in the villagers' community. This eventually turns into 
understanding, expertise, feelings which can be transferred and passed on continuously in daily ways of life. There is improvement and development of sets of knowledge appropriately, corresponding to changing situations of the community. There is also cultural succession of the community as options in solving problems of the community truly.

From the above definition, the definition "community knowledge" can be divided into 2 characteristics in order to see more concrete objects, including building understandings for executants to differentiate community knowledge for storage, collection and utilization more clearly. Characteristics of community knowledge can be divided according to characteristics of being touchable and utilization, consisting of 1) Knowledge of general data which has already been recorded and stored (explicit knowledge), namely general basic data of the community, area conditions, context, community background, community history, physical data and information, community cultures, traditions, social capital, state of society, economy, politics, government, community potentials, community organizations and relationships in the community and 2) Knowledge which is practical skills in conducting oneself, occupations and life qualities development, namely skill knowledge, techniques of practices, secrets of self-development, earning a living, solving problems in the community at the individual, household, organizational and network level, including communities. This knowledge is feeling rooted or hidden in knowledgeable people (tacit knowledge) which must be searched for, transferred and exchanged in the community. In action learning, if the definition of community knowledge in 2 characteristics as mentioned is considered, knowledge in the first characteristic is general data which have already been recorded and stored. The community learning center takes action in storing, collecting and managing the knowledge when it starts operating. At the beginning, it was the matter of building knowledge, understandings and awareness in roots and ways of community wisdom which we call promoting to know oneself and potentials of oneself. Knowledge in the second characteristic is knowledge of practical skills in self-existence, occupations and life qualities development. Currently, there is management for this in the community but not much when compared with the first characteristic. It is operational community knowledge, namely originating from observance and experiment, practices of people in the community. Knowledge is embedded in the people. There is succession through practices. There is mutual socialization. There is development, correction and application. There is learning from learning sources and from the nature. It is voluntary learning, not time limited, have goals to solve one's own problems, problems of families, groups, networks and community and knowing for implementation (Nonaka \& Takeuchi, 1995).

Therefore, sustainable community knowledge management shows strength in indicating, seeking for, storing, categorizing, distilling, exchanging, propagating techniques, methods of practices, secrets or cautions which were effective and successful in the past and were passed on up to now of leaders, groups, organizations and networks, including knowledgeable people, philosophers of fields in the community and 5) Distilling lesson learned is both a concept and an instrument to build learning. It is a method of knowledge management of teachers for self-reliance highland development whereby it is the process of extracting knowledge from working to be used as working capital for better upgrading (Phuwanatvichitr, 2015; Duangkaewruen, Phuwanatvichitr, \& Mangkang, 2016). This is in line with the study of Lilaporn Buasai (2004), Panich (2006), Plynoi (2010), Ministry of agriculture and cooperatives (2011) which presents correspondingly that distilling lessons learned is extracting tacit knowledge to be explicit knowledge. Results obtained from distilling lessons learned bring about lessons in the form of empirical sets of knowledge and mutual learning of process participants. This leads to adjusting of methods of thinking and changing ways of working to be more creative with qualities. The main key of distilling lessons must have knowledge sharing with mutual benefits, trust on oneself and other people. There is learning. Therefore, good lessons are valuable sets of knowledge and have power to build intellect in order to be used for integrated highland development.

\section{Conclusion}

At present, the highlands have digital media covering all areas. Traditional learning management is incapable of responding to disruptive technological changes. An important skill is a development of learning management to help students utilize digital resources in their learning. will want to manage learning in an interdisciplinary format and changing the curriculum to the curriculum of trans virtual competency to achieve equality and equality in society. which response to the management of education according to the Sustainable Development Goals (SDGs).

\section{Suggestions from the Research}

\subsection{Suggestions for Implementing Research Results}

The institute producing social studies teachers should develop to have the course training teacher to have 
thematic Interdisciplinary studies related to languages and cultures in transferring knowledge in line with ways of life of the highland community and suitable with students' age. This also includes developing techniques of learning management in order to build equality and to reduce ethnic prejudices of citizens in highlands such as ways of consumption, conditions, cultures, cultures and customs.

Social studies teachers should have skills of integrated language and culture (Content and Language Integrated Learning) before transferring. They should cover all community contexts which villagers know and they really exist in villagers' ways of life. Good medias should give examples of activities which the community conducts on the basis of customs and cultures of the community by inserting good virtues and ethnics of the community into purposes of media production for highland development.

Social studies teachers should use result assessment, focusing on real conditions. This is to enter action plots areas, visit students' houses, survey the amount of food sufficiency in the family and remaining amount of food from consumption for distribution. This reflects food security, debt-free state of highland community households.

\subsection{Suggestions for Next Research}

Regarding research results, it was found that teachers still lack planning learning connecting to and corresponding to real conditions in the community. There should be development of area-based curriculum integrating learning sources of the royal project in order to promote learning qualities according to real conditions of students in the area of the royal project in northern Thailand.

Regarding research results, it was found that media forms used in transferring knowledge did not correspond to the needs of communities with various ethnicities. There should be development of media forms with efficiency in knowledge management for developing students in communities in the area of the royal project of northern Thailand.

Regarding research results, it was found that guidelines of area-based learning management for sustainable highland community resources management of teachers of the community learning center have operation components consisting of facilitating, making participatory community plans, value-added community capital, building innovation of sets of knowledge and distilling lessons learned. There should be developing forms in knowledge management for student development of teachers in the Learning Center for Thai hill tribe communities in Northern Thailand.

\section{References}

Aekasing, B., \& Phromburom, T. (2001). Productivity of Highland Agriculture in the royal project development center. Economic Journal Chiang Mai University, 6(2), 48-63.

Awad, M. E., \& Ghaziri, M. H. (2004). Knowledge Management. Upper Saddle River, N. J.: Prentice-Hall.

Bamrungsetthapong, S., Tharnpanya, P., \& Satjaharuthai, K. (2020). Hybrid learning and the quality improvement of Thailand's education in the 21st century. Narkbhut Paritat Journal, Nakhon Si Thammarat Rajabhat University, 12(3), 213-224.

Buasai, L. (2004). Local Power: Synthesis Lesson of Community Research. Bangkok: Research Support Fund Office (Sor.Kor.Wor.).

Burlington, M. (2005). Information and Knowledge Management. Oxford: Elsevier.

Chantavanich, S. (2007). Methods of qualitative research. Bangkok: Publishing House of Chulalongkorn University.

Chatcharee, N. (2008). Participatory Agricultural Development. Bangkok: Publishing House Kasetsart University.

Daecharat, W. (2004). Process of Community Knowledge Management: Case Study of Kohsai sub-district, Khai Bangrachan district. Bangkok: Chulalongkorn University.

Dalkir, K. (2005). Knowledge Management in Theory and Practice. Oxford: Elsevier.

Dewey, J. (1963). Experience and Education. New York: Collier.

Duangkaewruen, N., Puwanatvichit, T., \& Mankang, C. (2016). Community Knowledge Management For building security in the land and reduce behaviors of damaging the environment of people in the community: Case study Mae Ta sub-district, Mae On District, Chiang Mai province. Journal MFU Connexion: Journal of Humanities and Social Sciences, 5(2), 45-70.

Forbes, S. (2003). Holistic Education: An Analysis of Its Ideas and Nature. Brandon, VT: Foundation for 
Educational Renewal.

Highland Research and Development Institute (Public Organization). (2012). Mutual learning under the project of transferring knowledge of the royal project and highland community potential development of 2007-2012. Chiang Mai: Royal Project Foundation.

Kaewpanya, N., Mangkhang, C., \& Dibyamandala, J. (2021). Community-based Transdisciplinary Learning Innovation in Social Studies Through Miang Wisdom for Promoting Green Citizenship of Secondary School Students. PSYCHOLOGY AND EDUCATION, 58(3), 875-884.

Mangkhang, C., \& Piriyatachagul, G. (2020). Development of area-based learning innovation through Miang culture to promote green citizenship for social studies teachers in Upper Northern Thailand. International Journal of Educational Policy Research and Revie, 7(1), 16-26.

Mangkhang, C., Jarupongputtana, C., Yimsawat, C., \& Buttong, C. (2015). The research report on local curriculum development through museums Culture of Ban Pa Dan Ethnic Community, Takatnuea sub-district, Mae Ta district, Lampoon province. Chiang Mai: Faculty of Education Chiang Mai University.

Metkarunchit, M. (2004). Participatory Educational Management. Bangkok: Book Point.

Miller, R. (2000). Caring for new life: Essays on holistic education. Brandon, VT: Foundation for Educational Renewal.

Ministry of Agriculture. (2011). Handbook of distilling lesson learned for agricultural promotion. Bangkok: Agricultural Promotion Research and Development Division Department of agricultural Promotion.

Natsupa, C. (2005). Guidelines and Research Method on Thai Society. Bangkok: Sangsun Publishing house.

Nonaka, I., \& Takeuchi, H. (1995). The Knowledge-Creating Company: How Japanese Companies Create the Dynamics of Innovation. New York: Oxford University Press. https://doi.org/10.1016/0024-6301(96)81509-3

Non-Formal Education Center Chiang Mai province. (2005). Summary report on the operation of non-formal educational management on highland Form of Mae Fah Luang Learning Center for Thai Hill Tribe Community (Sor.Sor.Cho). Chiang Mai: Non-Formal Education Management Office Ministry of Education.

Non-Formal Education Management Office. (2003). Summary report on supervision of northern non-formal education of the fiscal year 2003. Bangkok: Permanent Secretary Office, Ministry of Education.

Panich, V. (2012). Knowledge Management Edition for Practitioner. Bangkok: Mental Health.

Panich, V. (2012). Way of learning for students in the 21 st century. Bangkok: Sodsri-Saritwong Foundation.

Panyanuwat, A. (2014). The research report on worthiness assessment in managing special zone development for sustainable tourism. Bangkok: Special Zone Development Administrative Organization for Sustainable tourism (Public Organization).

Peter, M. S. (1990). The Fifth Discipline: The Art \& Practice of The Learning Organization. New York: Currency Doubleday.

Phra, P. K. (2013). Participation in making local development and budget plans. Bangkok: AP Graphic Design and Publishing Co, Ltd.

Plynoi, S. (2010). Various methods of distilling lessons and synthesizing knowledge (4th ed.). Bangkok: Siam Kunmajon Thai Commercial Bank limited (Public).

Potaka, D. (2006). Sustainable Development. Bangkok: Komal Kiemthong Foundation Publishing House.

Pothisita, C. (2007). Science and Art of Qualitative Research. Bangkok: Amarin Company.

Puwanatvichit, T. (2015). Concept of Public Welfare on the base of community resources: Alternatives for self-reliance of sustainable communities. Journal MFU Connexion: Journal of Humanities and Social Sciences, 4(2), 65-94

Romeratanapun, W. (2005). Social Capital. Bangkok: Project of building learning for the community to be happy (Sor.Ror.Sor).

Siribunpitak, P. (2012). Educational Management of Sustainable Development: Education Basic Economic, Social and Environmental Aspect Second Publishing. Bangkok: Faculty of Education Chulalongkorn University.

The United Nations. (2015). Transforming our world: the 2030 Agenda for Sustainable Development. Retrieved 
from https://sustainabledevelopment.un.org/post2015/transformingourworld/publication

Wullipodom, S. (2013). Failure in national education. Bangkok: Lek-Prapai Foundation Viriyapun.

Yin, K. R. (2014). Case study research design and methods (5th ed.). Thousand Oaks, CA: Sage. p. 282.

\section{Copyrights}

Copyright for this article is retained by the author(s), with first publication rights granted to the journal.

This is an open-access article distributed under the terms and conditions of the Creative Commons Attribution license (http://creativecommons.org/licenses/by/4.0/). 